\title{
SANKSI PIDANA TERHADAP PELAKU TINDAK PIDANA PERJUDIAN TOGEL (STUDI KASUS PUTUSAN PENGADILAN NEGERI BANGLI NOMOR 23/PID.B/2020/PNBLI)
}

\author{
I Dewa Ayu Mira Pradewi, I Nyoman Gede Sugiartha, I Ketut Widia \\ Fakultas Hukum Universitas Warmadewa, Denpasar-Bali, Indonesia \\ lezzylorenza@gmail.com, nyomansugiartha@gmail.com, ketut_widia@gmail.com
}

\begin{abstract}
Abstrak
Perjudian merupakan taruhan dengan nilai-nilai risiko yang sengaja atau sesuatu yang dianggap berharga, dengan menyadari risiko. Penelitian ini dirumuskan untuk mengetahui alasan maraknya tindak pidana perjudian togel masih marak terjadi di masyarakat, serta untuk mengetahui pertimbangan hakim dalam menjatuhkan putusan terhadap pelaku tindak pidana perjudian togel. Tipe penelitian yang digunakan adalah tipe penelitian hukum normatif. Metode pendekatan yang digunakan adalah pendekatan perundang-undangan. Sedangkan teknik pengumpulan bahan hukum yang digunakan adalah dengan menganalisa putusan pengadilan. Adapun hasil penelitian ini menunjukkan bahwa maraknya perjudian di masyarakat Indonesia disebabkan oleh beberapa faktor, salah satunya pengenaan Sanksi Pidana terhadap pelaku tindak pidana perjudian yang terlalu ringan. Sedangkan perkara Putusan Nomor 23/PID.B/2020/PNBLI tentang perjudian togel disebabkan oleh faktor ekonomi dan lingkungan yang melibatkan Terdakwa Nyoman Pageh dan dikenakan sanksi pidana berupa pidana penjara selama 5 bulan dengan dakwaan melanggar ketentuan Pasal 303 ayat (1) KUHP jo Pasal 2 UU No. 7 Tahun 1974. Pertimbangan hakim dalam putusan didasarkan dengan pertimbangkan hakim yuridis. Adapun keadaan yang memberatkan adalah, perbuatan Terdakwa tidak mendukung program pemerintah dalam pemberantasan perjudian, sedangkan keadaan yang meringankan adalah, Terdakwa menyesal dan berjanji tidak mengulangi perbuatannya lagi, Terdakwa berlaku sopan di persidangan, dan Terdakwa sebagai tulang punggung keluarga.
\end{abstract}

Kata kunci: Perjudian Togel; Sanksi; Tindak Pidana.

\begin{abstract}
Gambling is a bet with deliberate risk values or something that is considered valuable, by being aware of the risk. This study was formulated to determine the reasons for the rampant crime of lottery gambling in the community, as well as to find out judges' considerations in making decisions against perpetrators of lottery gambling. The type of research used is the type of normative legal research. The approach method used is the statutory approach. Meanwhile, the technique of collecting legal materials used is by analyzing court decisions. The results of this study indicate that the prevalence of gambling in Indonesian society is caused by several factors, one of which is the imposition of criminal sanctions against perpetrators of gambling crimes that are too light. While the case of Decision Number 23 / PID.B / 2020 / PNBLI regarding lottery gambling was caused by economic and environmental factors involving the Defendant Nyoman Pageh and was subject to criminal sanctions in the form of imprisonment for 5 months on the charge of violating the provisions of Article 303 paragraph (1) of the Criminal Code in conjunction with Article 2 Law no. 7 of 1974. Judges 'considerations in decisions are based on juridical judges' consideration. As for the burdensome circumstances, the Defendant's actions did not support the government program in eradicating gambling, while the mitigating circumstances were, the Defendant was sorry and promised not to repeat his actions again, the Defendant behaved politely at the trial, and the Defendant was the backbone of the family.
\end{abstract}

Keywords: Criminal Act; Sanctions; Lottery Gambling.

\section{PENDAHULUAN}

Judi bukan hal baru bagi rakyat Indonesia, karena permainan judi telah ada di sekitar sebelumnya dan berkembang seiring dengan zaman (Prasetyo \& Setyowati, 2019; Suharya, 2019). Judi untuk komunitas adalah salah satu bentuk permainan yang sangat populer dan tersebar luas dalam kehidupan masyarakat, karena permainan judi dianggap mengandung nilai hiburan (Zurohman, Astuti, \& Sanjoto, 2016). Perjudian merupakan hal yang tidak dapat dihindari terjadi di masyarakat salah satunya 
terdapat dalam Tribrata News Portal Berita Resmi Polri yang setiap harinya menerbitkan informasi mengenai peristiwa kriminalitas. Pada tanggal 29 Januari 2019 Tribrata News Portal Berita Resmi Polri menerbitkan berita harian yang mengungkap peristiwa kriminal jenis perjudian togel. Dengan adanya peristiwa tersebut perjudian menjadi salah satu perbuatan yang dapat menimbulkan permasalahan dalam kehidupan bermasyarakat. Jumlah kasus yang telah ditegakkan oleh penegakan hukum adalah salah satu bukti bahwa perjudian di Indonesia tidak dapat diberantas. Judi secara umum dipandang sebagai kejahatan. Fitur perjudian atau berpartisipasi pada awalnya tidak diperbolehkan dengan pasal 542 dari KUHP, tetapi atas peraturan yang telah diundangkan pada Pasal 2 ayat (4) dan UU No. 7 tahun 1974, itu telah dikonversi sepenuhnya menjadi ketentuan kriminal yang diatur dalam Pasal 303 KUHP.

Dalam Putusan Pengadilan Negeri Bangli Nomor 23/PID.B/2020/PNBLI terdapat kasus judi lotre yang melibatkan Nyoman Pageh (terdakwa) pada tanggal 14 Maret 2020 pukul 17.00WITA tidak mendapatkan izin, yaitu berniat memasarkan ataupun menyediakan Peluang untuk pemirsa publik untuk memainkan lotere tipe judi. Perbuatan tersebut berawal ketika Nyoman Pageh (terdakwa) menyiapkan alat berupa 1 buah bolpoin warna silver kombinasi warna orange yang dipakai untuk menulis angka pasangan judi togel, selanjutnya terdakwa menawarkan kepada saksi Wayan Budiasa dan saksi Made Sedana. Setelah mendengar hal tersebut saksi Wayan Budiasa dan saksi Made Sedana tertarik dan mengatakan kepada terdakwa Nyoman Pageh untuk ikut memasang taruhan judi togel tersebut dan akan menitipkannya kepada terdakwa Nyoman Pageh.

Berdasarkan uraian untuk lebih mengetahui tindak pidana perjudian togel masih marak terjadi di masyarakat, dan untuk mengetahui pertimbangan Hakim dalam menjatuhkan putusan terhadap pelaku tindak pidana perjudian togel.

\section{METODE PENELITIAN}

Jenis penelitian yang digunakan dalam penelitian ini adalah penelitian hukum normatif. Penelitian hukum normatif ialah penelitian hukum yang dimana konsepnya telah tertulis baik itu dalam perUUan, ataupun norma yang menjadi tolak ukur perilaku masyarakat yang wajar (Amiruddin \& Asikin, 2004). Mengenai sumber bahan hukum yang digunakan terbagi atas Bahan Hukum Primer adalah bahan hukum yang utama yang menjadi dasar kajian penulisan ini, Bahan Hukum sekunder adalah adalah bahan hukum yang digunakan untuk menunjang atau membantu dalam memberikan pemahaman-pemahaman dan gambaran- gambaran serta teori-teori hukum yang digunakan untuk mengulas dan memecahkan persoalan-persoalan yang akan diteliti dalam penelitian (Ahmad, 2008). Untuk memperoleh bahan hukum primer dengan memperdalam putusan pengadilan, untuk memperoleh bahan hukum sekunder dengan metode penelitian studi kasus di Pengadilan Negeri Bangli dalam bentuk Putusan.

\section{HASIL DAN PEMBAHASAN}

\section{Maraknya Tindak Pidana Perjudian Togel yang Terjadi di Masyarakat}

Dalam berjudi dituntut adanya suatu kemampuan untuk mengambil resiko dan ketangguhan untuk menghadapi ketidakpastian. Namun keberhasilan sesaat dapat membuat orang yang melakukan aktivitas perjudian menjadi terlena. Tanpa disadari orang tersebut menjadi malas dan menghalalkan segala cara untuk mendapatkan uang yang dipakai sebagai taruhan. Namun faktor kesenangan dan tantangan itulah yang merupakan kenikmatan tersendiri, yang seringkali tidak dapat ditolak. Sebagian orang yang mengambil resiko dengan mempertaruhkan uangnya di atas meja judi, secara kebetulan menang dan merasa mudah mendapatkan uang. Sehingga orang tersebut akan berusaha mendapatkan uang yang lebih besar lagi dengan mempertaruhkan uangnya kembali di atas meja judi, begitu seterusnya sampai akhirnya terjebak dalam lingkungan permainan judi yang sulit untuk dihentikan. Seiring dengan semakin banyak aspek yang perlu dipertimbangkan sebagai akibat dari interaksi hubungan sebab-akibat dengan lingkungan, judi sering digunakan dan dimanfaatkan oleh manusia yang mencoba mengadu nasib. Oleh karena itu tidak mengherankan pada budaya atau kelompok tertentu judi merupakan suatu pranata sosial. Pada beberapa suku bangsa di Indonesia, ditemukan aktivitas judi sebagai bagian aktivitas budaya lingkungan hidup mereka.

Kebiasaan-kebiasaan yang sudah mengakar dan menjadi suatu tradisi ini pada dasarnya mustahil untuk diberantas. Masyarakat Indonesia yang sejak zaman dahulu banyak berhubungan dengan saudagar saudagar Cina juga diperkenalkan dengan permainan judi, yang dalam 
perkembangannya mempengaruhi budaya masyarakat di beberapa wilayah Indonesia. Hingga saat ini, tidak ada yang dapat menjelaskan secara pasti kapan perjudian mulai dikenal di muka bumi ini dan siapa yang pertama kali memperkenalkannya. Namun, dapat dikatakan bahwa perjudian merupakan aktivitas yang telah dilakukan oleh manusia sejak dulu kala, bahkan sejak adanya peradaban di muka bumi. Judi yang terjadi pada orang Indonesia disebabkan oleh beberapa faktor yang mendukung kejahatan. Faktor-faktor yang menyebabkan perjudian adalah sebagai berikut (Hamzah, 2008)

1. Faktor Ekonomi

2. Faktor Agama

3. Faktor Budaya

4. Faktor Lingkungan

5. Faktor Belajar

6. Faktor Adanya Peluang Untuk Menang

7. Faktor Keterampilan

Berdasarkan uraian diatasi jika dikaitkan dengan perkara No.23/PID.B/2020/PNBLI, perbuatan tindak pidana perjudian yang dilakukan dalam perkara tersebut disebabkan oleh faktor ekonomi dan faktor lingkungan. Kerana dengan modal yang sangat kecil mereka berharap dapat memperoleh keuntungan yang besar atau menjadi kaya dalam seketika tanpa usaha keras. Di samping itu, tindakan masyarakat dalam penurunan jiwa rohani akan menyebabkan masyarakat yang mudah terjejas, mudah dibujuk untuk meneruskan tindakan yang membawa kepada perbuatan negatif dalam hal ini adalah tindakan perjudian.

\section{Pertimbangan Hakim dalam Menjatuhkan Putusan terhadap Pelaku Tindak Pidana Perjudian Togel}

Pertimbangan hakim adalah pendapat yang dipergunakan hakim untuk suatu pertimbangan dimana akan menjadi landasan hakim untuk menjatuhkan sebuah putusan dalam persidangan. Putusan hakim pada praktiknya di persidangan sebelum pertimbangan yuridis ini dibuktikan, fakta-fakta hukum yang terungkap dalam persidangan akan terlebih dahulu akan ditarik oleh hakim. Hakim mengambil sebuah konklusi yaitu sebagai sebuah pertimbangan yuridis untuk menegaskan kembali fakta-fakta yang telah terungkap (Wijayanto, 2012). Menurut Mardjono Reksodiputro, karena tujuannya yang dapat 'mengganggu atau merusak' nama baik seseorang dalam masyarakat, maka pidana tambahan ini hanya dapat dipertimbangkan oleh hakim apabila memang hal tersebut diancamkan dalam rumusan tindak pidana (Reksodiputro, 2007). Hakim dalam menjatuhi hukuman pidana tidak boleh lebih sedikit dari batas yang telah ditentukan ataupun sebaliknya tidak boleh lebih tinggi menjatuhi hukuman yang telah diatur dalam UU (Rifai, 2010). Berdasarkan analisa kasus penulis, adapun yang menjadi pertimbangan dalam perkara perjudian togel berdasarkan Putusan Pengadilan Negeri Bangli No.23/PID.B/2020/PNBLI, diantaranya terdakwa diajukan ke persidangan di Pengadilan Negeri Bangli oleh Jaksa Penuntut Umum yang telah didakwa dengan dakwaan melanggar ketentuan Pasal 303 ayat (1) ke KUHP ke-2 Jo Pasal 2 UUNo. 7 Republik Indonesia tahun 1974 dalam tuduhan jaksa penuntut umum. Dan untuk membuktikan tuduhan jaksa penuntut umum telah mengirimkan 4 saksi, yakni 1) Nyoman Wira Wirawan, SH, 2) Febryanto Putra Sanjaya, SH, 3) I Wayan Budisa, 4). Made Sedana, yang telah memberikan informasi di bawah sumpah sebelum persidangan terkandung dalam risalah persidangan.

Barang bukti yang diajukan JPU sebagai berikut

1. Uang Tunai Rp. 45.000,-

2. 1 ballpoint warna silver kombinasi orange

3. 1 lembar sobekan kertas yang berisi pasangan angka togel.

Berdasarkan bukti dan bukti yang disampaikan, fakta-fakta hukum berikut diperoleh terdakwa telah diamankan oleh petugas Kepolisian pada 14 Maret 2020 sekira pukul 17.00 Wita, bertempat di pinggir Jalan Raya, Desa Tiga, Kecamatan Susut, Kabupaten Bangli terkait melakukan permainan judi jenis togel yang berperan sebagai pengecer yaitu yang menerima titipan angka yang selanjutnya akan Terdakwa setor/pasang kepada seseorang yang Terdakwa tidak kenal namanya dan biasanya bertemu di sebelah warung yang berlokasi di Desa Tiga, Kecamatan Susut, Kabupaten Bangli. Pada hari Senin tanggal 09 Maret 2020 pukul 15.00 wita Saksi I Nyoman Wira Wirawan, SH bersama rekan unit opsnal mendapat informasi dari masyarakat bahwa di daerah Desa Tiga, Kecamatan Susut, Kabupaten Bangli ada seseorang yang bermain judi jenis togel selanjutnya Saksi bersama rekan opsnal yang 
lainnya melakukan penyelidikan, dan pada tanggal 14 Maret 2020 sekira pukul 17.00 wita Saksi bersama rekan opsnal lain melihat 2 orang yang berboncengan mengendarai sepeda motor di Jalan Raya Desa Tiga, Kecamatan Susut, Kabupaten Bangli yang dicurigai memungut pemasangan judi jenis togel, kemudian Saksi bersama rekan unit opsnal lainnya mencegah dan menghentikan kedua orang tersebut setelah diintrogasi awalnya Terdakwa mengelak tidak mengakui melakukan permainan judi togel dan pada saat diperiksa ditemukan pada Terdakwa barang bukti berupa uang tunai sebesar Rp. 45.000,-, 1 buah bolpoin warna silver kombinasi orange, dan 1 lembar sobekan kertas yang berisi pasangan angka togel.

Terdakwa saat diamankan oleh Polisi sedang berada di pinggir jalan untuk memasang titipan angka togel yang Terdakwa terima dan pada saat itu uang tunai sebesar Rp. 45.000,- dan 1 lembar sobekan kertas yang berisi pasangan angka togel tersebut terdakwa pegang dengan menggunakan tangan kiri sedangkan 1 buah bolpoin ditemukan di tempat terdakwa bekerja. Pasangan taruhan yang dititipkan oleh Saksi Made Sedana sebesar Rp. 15.000,- dan taruhan angka yang dipasang oleh Saksi Wayan Budiasa sebesar Rp. 30.000,- sudah diamankan oleh Polisi. Terdakwa menerangkan bahwa permainan judi jenis togel dilakukan dengan cara menerima pasangan angka togel di tempatnya bekerja secara langsung dari pemasang, selanjutnya menurut keterangan Terdakwa pasangan tersebut disebarkan kepada seseorang namun Terdakwa tidak mengenal secara jelas nama maupun alamat orang yang disetorkan dan Terdakwa bertemu dengan orang tersebut di warung yang berlokasi di Desa Tiga, Kecamatan Susut, Kabupaten Bangli. Setelah itu Terdakwa menunggu sampai keluar pengumuman dan kemudian mencocokkan dengan angka yang dipasang taruhan oleh pemain untuk mengetahui menang dan kalahnya. Bagi pemain yang angkanya cocok atau sama dengan angka yang keluar itu dinyatakan sebagai pemenang dan bagi pemenang akan mendapatkan keuntungan.

Terdakwa masih ingat angka-angka yang dipasang oleh Saksi Made Sedana adalah angka 20x2, 99x3, 19x2, 90x3, 31x2, 37x3 dan angka-angka yang dipasang taruhan oleh Saksi I Wayan Budiasa adalah angka $21 \times 5,41 \times 5,47 \times 7,98 \times 7,98 \times 10,89 \times 3$. Sebelum Terdakwa ditangkap oleh Polisi sudah sempat menerima titipan pasangan taruhan judi togel dari Saksi Made Sedana dan Saksi I Wayan Budiasa dan pada saat itu pasangan titipan tersebut sudah Terdakwa setorkan namun yang terakhir ini belum sempat disetor karena keburu ditangkap Polisi. Terdakwa menerima titipan angka taruhan judi togel dengan cara menerima catatan angka yang sebelumnya sudah ditulis angka angka oleh Saksi Made Sedana dan Saksi I Wayan Budiasa yaitu menggunakan kertas rokok dan beserta uang sesuai dengan besar taruhan yang dipasang dan Saksi Made Sedana sudah pernah titip togel 3 kali dan Saksi I Wayan Budiasa sebanyak 2 kali. Pada saat Saksi Made Sedana dan Saksi I Wayan Budiasa titip pasang judi togel keduanya tidak pernah menang atau beruntung. Tujuan Terdakwa sebagai pengecer untuk mendapat penghasilan tambahan yang kemudian digunakan untuk kebutuhan seharihari.Terdakwa tahu sifat permainan judi perjudian adalah untung-untungan. Terdakwa melakukan permainan judi lotre, tidak ada izin dari otoritas resmi. Selanjutnya, Hakim akan mempertimbangkan apakah berdasarkan fakta-fakta UU di atas, terdakwa dapat dinyatakan telah melakukan kejahatan yang didakwa dengan dakwaan berbentuk tunggal, yang sebagaimana diatur dalam Pasal 303 ayat (1) Untuk KUHP dalam Pasal 2 UUNo. 7 Tahun 1974, yang elemennya adalah sebagai berikut:

1. Unsur Barang Siapa

Jaksa Penuntut Umum telah menghadapi seseorang bernama Nyoman Pageh, yang setelah pemeriksaan persidangan sebagai terdakwa, berdasarkan kesaksian saksi dan pernyataan terdakwa sendiri tentang identitas terdakwa. Pada persidangan itu berlaku untuk terdakwa, orang tersebut disebut oleh identitas Kejaksaan Umum sesuai dengan identitas terdakwa sebagaimana dinyatakan dalam dakwaan No. REG. PERKARA PDM-08/BANGLI/05/2020 tanggal 12 Mei 2020, sehingga tidak terjadi error in persona. Berdasarkan pertimbangan ini, Hakim, berpendapat bahwa unsur pertama dari barangsiapa terpenuhi.

2. Unsur Tanpa menerima izin untuk dengan sengaja menawarkan atau memberikan kesempatan kepada masyarakat umum untuk bermain judi atau dengan sengaja berpartisipasi dalam perusahaan untuk itu, dengan tidak peduli apakah akan menggunakan kesempatan untuk menjadi persyaratan atau perlunya sesuatu yang prosedur. Berdasarkan fakta yang terungkap di persidangan dari keterangan Saksi-Saksi, keterangan Terdakwa dan barang bukti, diperoleh fakta bahwa Terdakwa diamankan petugas Kepolisian pada tanggal 14 Maret 2020 sekira pukul 17.00 Wita, bertempat di pinggir Jalan Raya, Desa Tiga, Kecamatan Susut, Kabupaten Bangli terkait melakukan permainan judi jenis togel yang berperan sebagai pengecer yaitu menerima 
titipan angka yang selanjutnya akan Terdakwa setor/pasang kepada seseorang dan pada saat diperiksa ditemukan pada Terdakwa barang bukti berupa uang tunai sebesar Rp. 45.000,-, 1 buah bolpoin warna silver kombinasi orange, dan 1 lembar sobekan kertas yang berisi pasangan angka togel. Terdakwa menerima titipan No. togel sebagai pengecer dengan cara menerima catatan angka yang sebelumnya sudah ditulis angka angka oleh Saksi Made Sedana 20x2, 99x3, 19x2, 90x3, 31x2, 37x3 dan saksi I Wayan Budiasa 21x5, 41x5, 47x7, 99x10, 89x3 yaitu menggunakan kertas rokok dan beserta uang sesuai dengan besar taruhan yang dipasang Made Sedana sebesar Rp. 15.000,- dan taruhan angka yang dipasang Wayan Budiasa sebesar Rp. 30.000,- yang selanjutnya akan Terdakwa setor/pasang kepada seseorang yang Terdakwa tidak kenal namanya dan biasanya bertemu di sebelah warung yang berlokasi di Desa Tiga, Kecamatan Susut, Kabupaten Bangli.

Permainan judi jenis togel dilakukan dengan cara menerima pasangan angka togel di tempatnya bekerja secara langsung dari pemasang, selanjutnya Terdakwa menerangkan bahwa pasangan tersebut disetorkan kepada seseorang namun Terdakwa tidak mengenal secara jelas nama maupun alamat yang disetorkan dan terdakwa kenal dengan orang tersebut di warung yang berlokasi di Desa Tiga, Kecamatan Susut, Kabupaten Bangli. Setelah itu Terdakwa menunggu sampai keluar pengumuman dan kemudian mencocokkan dengan angka yang dipasang taruhan oleh pemain untuk mengetahui menang kalahnya bagi pemain, yang angkanya cocok atau sama dengan angka yang keluar itu yang dinyatakan sebagai pemenang. Bagi pemenang akan mendapatkan keuntungan untuk 2 angka sebesar taruhan dikalikan Rp.60.000,-, untuk 3 angka dikalikan Rp. 350.000,-, dan untuk 4 angka Terdakwa tidak mengetahuinya. Terdakwa menerima titipan angka taruhan judi togel dari saksi Made Sedana sebanyak 3 kali dan saksi I Wayan Budiasa sebanyak 2 kali. Keduanya tidak pernah menang atau beruntung, sedangkan titipan yang terakhir belum sempat disetorkan karena keburu ditangkap polisi. Terdakwa dalam menjual No. togel tersebut tidak ada izin dari pejabat yang berwenang dan orang yang menjadi penitip No. togel adalah masyarakat umum yang berkeinginan membelinya.

Sifat dari permainan No. togel tersebut untung-untungan karena setiap penitip belum pasti menang, dimana tujuan Terdakwa dalam menjual No. togel tersebut adalah untuk mendapatkan penghasilan tambahan selain sebagai petani/pekebun. Berdasarkan uraian diatas Majelis Hakim berpendapat bahwa perbuatan Terdakwa sebagai pengecer dalam permainan judi jenis togel dikehendakinya karena Terdakwa mendapatkan keuntungan sebagai penjual eceran, sedangkan Terdakwa mengetahui bahwa permainan No. togel termasuk permainan bersifat untung-untungan yaitu judi. Terdakwa menyadari bahwa mengadakan permainan judi bagi khalayak umum tersebut dilarang karena tidak mendapatkan izin dari pihak yang berwenang. Berdasarkan pertimbangan tersebut Majelis Hakim berpendapat bahwa unsur kedua yaitu Tanpa Mendapat Izin dengan sengaja menawarkan atau memberi kesempatan kepada khalayak umum untuk bermain judi telah terpenuhi.

\section{SIMPULAN DAN SARAN}

\section{Simpulan}

Berdasarkan hasil penelitian di atas, maka dapat disimpulkan bahwa maraknya perjudian sosial di Indonesia disebabkan oleh berbagai faktor, salah satunya adalah pemberian sanksi pidana kepada pelaku perjudian yang terlalu ringan. Menurut Pasal 303 (1) KUHP, hukuman maksimal bagi pelaku perjudian adalah 10 tahun penjara atau denda 25 juta rupiah. Perkara Putusan No.23/PID.B/2020/PNBLI, perbuatan tindak pidana perjudian togel yang dilakukan dalam perkara tersebut disebabkan oleh faktor ekonomi dan faktor lingkungan. Perkara yang melibatkan Terdakwa NYOMAN PAGEH dikenakan sanksi pidana berupa pidana penjara selama 5 bulan dengan dakwaan melanggar ketentuan Pasal 303 ayat (1) ke-2 KUHP jo Pasal 2 UU Republik Indonesia No. 7 Tahun 1974. Pertimbangan hakim dalam menjatuhkan putusan dalam perkara Putusan No. 23/PID.B/2020/PNBLI hakim mempertimbangkan dengan pertimbangan hakim yang bersifat Yuridis, yaitu hal-hal yang memberatkan dan hal-hal yang meringankan. Adapun keadaan yang memberatkan adalah, perbuatan Terdakwa tidak mendukung program pemerintah dalam pemberantasan perjudian, sedangkan keadaan yang meringankan adalah, Terdakwa menyesal dan berjanji tidak mengulangi perbuatannya lagi, Terdakwa berlaku sopan di persidangan, dan Terdakwa sebagai tulang punggung keluarga. Sehingga hakim menjatuhkan hukuman selama 5 bulan. 


\section{Saran}

Berdasarkan simpulan tersebut diatas, dapat dikemukakan saran kepada para pihak terkait, sebagai berikut yakni Sebagai generasi penerus bangsa, diharapkan kepada seluruh masyarakat agar menghindari perilaku yang menyimpang salah satunya adalah perjudian jenis togel, karena perjudian merupakan kejahatan yang dapat memberikan dampak buruk bagi masyarakat. Selain itu dibutuhkan kondisi penegak hukum yang konsisten agar proses pemidanaan bisa memberi efek jera bagi Terdakwa sehingga kasus seperti ini tidak terjadi lagi. Kemudian, majelis hakim dalam memberi putusan tindak pidana perjudian diharapkan mempertimbangkan kepentingan bersama, agar dengan putusan tersebut dapat menghasilkan kedamaian dan ketentraman bagi masyarakat, dan tentunya dapat memberi efek jera bagi Terdakwa. Selain itu Majelis Hakim diharapkan dapat memberikan putusan seadil-adilnya sesuai dengan fakta hukum.

\section{DAFTAR PUSTAKA}

Ahmad, B. (2008). Metode Penelitian Hukum. Bandung: Pustaka Setia.

Amiruddin, \& Asikin, Z. (2004). Pengantar Metode Penelitian Hukum. Jakarta: PT. RajaGrafindo Persada. Hamzah, A. (2008). Asas-asas Hukum Pidana. Jakarta: Rineka Cipta.

Prasetyo, I. A., \& Setyowati, I. (2019). Upaya Kepolisian dalam Menanggulangi Tindak Pidana Perjudian Kartu Remi (Studi Kasus di Wilayah Hukum Polsek Wonosalam Kabupaten). In KONFERENSI ILMIAH MAHASISWA UNISSULA (KIMU) 2 (pp. 604-621). Semarang: Universitas Islam Sultan Agung.

Reksodiputro, M. (2007). Pembaharuan Hukum Pidana Kumpulan Karangan Buku Keempat, Jakarta. Jakarta: Pusat Pelayanan Keadilan dan Pengabdian Hukum.

Rifai, A. (2010). Penemuan Hukum oleh Hakim dalam Persfektif Hukum Progresif. Jakarta: Sinar Grafika. Suharya, R. (2019). Fenomena Perjudian di Kalangan Remaja. EJournal Sosiatri-Sosiologi, 7(3), 326-340. Wijayanto, R. (2012). Asas-Asas Hukum Pidana Indonesia. Bandung: Mandar Maju.

Zurohman, A., Astuti, T. M. P., \& Sanjoto, T. B. (2016). Dampak Fenomena Judi Online terhadap Melemahnya Nilai-Nilai Sosial pada Remaja (Studi di Campusnet Data Media Cabang Sadewa Kota Semarang). Journal of Educational Social Studies, 5(2), 156-162. 